Hydrology and Earth System Sciences, 5(4), 629-644 (2001) C $\quad$ EGS

\title{
Towards understanding tree root profiles: simulating hydrologically optimal strategies for root distribution
}

\author{
M.T. van Wijk and W. Bouten \\ Institute of Biodiversity and Ecosystem Dynamics (IBED), Physical Geography and Soil Science, Universiteit van Amsterdam, Nieuwe Achtergracht 166,1018 WV \\ Amsterdam, The Netherlands
}

Email for corresponding author: Mark.van.Wijk@ed.ac.uk

\begin{abstract}
In this modelling study differences in vertical root distributions measured in four contrasting forest locations in the Netherlands were investigated. Root distributions are seen as a reflection of the plant's optimisation strategy, based on hydrological grounds. The 'optimal' root distribution is defined as the one that maximises the water uptake from the root zone over a period of ten years. The optimal root distributions of four forest locations with completely different soil physical characteristics are calculated using the soil hydrological model SWIF. Two different model configurations for root interactions were tested: the standard model configuration in which one single root profile was used (SWIF-NC), and a model configuration in which two root profiles compete for the same available water (SWIF-C). The root profiles were parameterised with genetic algorithms. The fitness of a certain root profile was defined as the amount of water uptake over a simulation period of ten years. The root profiles of SWIF-C were optimised using an evolutionary game. The results showed clear differences in optimal root distributions between the various sites and also between the two model configurations. Optimisation with SWIF-C resulted in root profiles that were easier to interpret in terms of feasible biological strategies. Preferential water uptake in wetter soil regions was an important factor for interpretation of the simulated root distributions. As the optimised root profiles still showed differences with measured profiles, this analysis is presented, not as the final solution for explaining differences in root profiles of vegetation but as a first step using an optimisation theory to increase understanding of the root profiles of trees.
\end{abstract}

Key-words: forest hydrology, optimisation, roots

\section{Introduction}

Root systems control an important part of the fluxes in the global hydrological cycle. Root systems largely control the partitioning of water fluxes to the atmosphere and groundwater (Canadell et al., 1996). Rooting depth is an important parameter in models of the general atmospheric circulation (GCMs), and the surface climate simulated with these models is sensitive to rooting depth changes (Kleidon and Heimann, 2000). Despite a long history of study of the dynamics of root distributions, experimental knowledge of the determining processes remains inadequate (Harper et al., 1991).

Jackson et al. (1996) give a thorough synthesis of existing data on root distributions. Root distributions must be included in models of the partitioning of water fluxes to the atmosphere and groundwater, soil litter decomposition, carbon sequestration and nutrient cycling. Jackson et al.
(1996) describe cumulative root fractions, and the parameters of an asymptotic equation are determined for various plant functional groups (grasses, shrubs and trees).

These distributions are static representations of the dynamic inter-relationship between soil and plant. Present knowledge of the dynamics and the effects of this interrelationship is limited. At the moment, root growth models being developed include empirical relations between soil physical characteristics (aeration, wetness, etc.) and root growth potentials (Asseng et al., 1997). In most cases, these models do not include a root growth strategy that optimises the amount of nutrients and/or water captured by the roots.

Application of an optimisation strategy to the parameterisation of root models can enhance our understanding of how the root compartment of the forest ecosystem reacts to its environment. Optimisation strategies have been applied successfully in the modelling of stomatal 
behaviour (Cowan, 1977; Mäkelä et al., 1996). Compared to site-specific parameterised models, application of the optimality hypothesis will, in most cases, lead to a lower performance but to increased general applicability. Otherwise, precise site-specific parameterisation of the root profile in hydrological models is difficult. Measurements of root profiles are very difficult, especially the distinction between different kinds of roots and the quantification of their functionality in extracting water from the soil (Olsthoorn, 1998).

In this study, large differences between vertical root distributions in different forest locations are explained in terms of a hydrological optimisation strategy. The 'optimal' root distribution is defined as that which maximizes soil water uptake over a period of ten years. This 'optimal' root system therefore reflects the long-term hydrological characteristics of the system and can then be a starting point of analyses of reactions of the root system to short term events in the system.

In this study on hydrological 'optimality' different root distributions are compared in an analysis based purely on simulation results, using the soil hydrological model SWIF (Tiktak and Bouten, 1992). In this theoretical analysis, two different model configurations were tested in the optimisation procedure: the standard model configuration of SWIF in which one single root profile was used and a model configuration in which two root profiles compete for the available water. In this way, the effects of competition between individual trees on simulated root distribution were tested. The analysis does not deal with inter-annual root growth strategies, but tries only to determine which 'static' root distribution results in the highest water uptake. The results of the competition and non-competition analyses are compared and discussed, and a first link of the results of this optimisation, which ignores effects of, for example, nutrients and short-term root growth, with measured root profiles is made.

\section{Materials and methods}

\section{SITE DESCRIPTION}

Four sites have been analysed in this study, Appelscha, Buunderkamp, Speuld and Winterswijk. All sites have been subject to detailed study: Appelscha by Musters (1998), Buunderkamp by Tietema (1992) and Speuld for the hydrological research part by Bouten (1992) and the root research by Olsthoorn (1998) and Winterswijk by Bouten (1992) and Tietema (1992). An overview of the soil profiles used in this model analysis is given in Fig. 1.

Appelscha $\left(52^{\circ} 58^{\prime} \mathrm{N}, 6^{\circ} 15^{\prime} \mathrm{E}\right)$ is a 0.11 ha Austrian pine (Pinus nigra var. 'nigra') stand within a larger homogeneous stand of 54-year-old pines with a density of 640 tree ha $^{-1}$. The height of the tree averages $10 \mathrm{~m}$ and the projected leaf area index is low (between $1.4-2.4 \mathrm{~m}^{2} \mathrm{~m}^{-2}$ ). The under-storey vegetation consists of several grass (Deschampsia flexuosa (L.) Trin., Molinia caerula (L.) Moench.) and moss species (Polytrigum spec.) and heather plants (Erica tetralix L. and Calluna vulgaris (L.) Hull.). The mineral soil consists of an undulating drift sand layer over a flat layer of non-rootable cover sand, consisting of medium fine sand. The soil is acid and classified as a Cambic Arenosol. The site has a shallow groundwater table fluctuating around the top of the cover sand during the winter and 1-2 $\mathrm{m}$ deeper in dry summers. More detailed information on the research site is given by Musters and Bouten (1999) and Musters et al. (2000).

Buunderkamp $\left(52^{\circ} 02^{\prime} \mathrm{N}, 5^{\circ} 48^{\prime} \mathrm{E}\right)$ is part of a large forested area and consists of 60 year-old oaks (Quercus robur). The soil is classified as a Fimic Anthrosol and is well-drained, podzolic, sandy and acid. At about $40 \mathrm{~cm}$ depth there is a buried, relatively rich organic sandy layer underlain by a coarse angular sand layer. The parent materials are preglacial with fluviatile deposits of the river Rhine. The ground water table is very deep. More detailed information on the research site is given by Tietema (1992).

Speuld is a 2.5 ha Douglas-fir (Pseudotsuga menziessii (Mirb.) Franco) stand within a large forested area near the township of Garderen $\left(52^{\circ} 13^{\prime} \mathrm{N}, 5^{\circ} 48^{\prime} \mathrm{E}\right)$. The stand is a dense forest with 780 trees ha ${ }^{-1}$ without an under-storey and was planted in 1962. Mean tree height between 1990 and 1992 was $22 \mathrm{~m}$. Projected leaf area index varied between 7.8 and $10.5 \mathrm{~m}^{2} \mathrm{~m}^{-2}$. The soil is a well drained Haplic Podzol, and consists of fluviatile deposits with textures ranging from fine sand to sandy loam. The groundwater table is at $40 \mathrm{~m}$ depth. The 30-year mean rainfall is $834 \mathrm{~mm} \mathrm{y}^{-1}$. More detailed information on the research site is given by Tiktak and Bouten (1994).

The Winterswijk location is part of a $0.1 \mathrm{~km}^{2}$ forest lowland catchment in the eastern part of the Netherlands $\left(52^{\circ} 00^{\prime} \mathrm{N}, 6^{\circ} 40^{\prime} \mathrm{E}\right)$. The forest consists predominantly of oaks (Quercus robur) about 120 years old, $20-25 \mathrm{~m}$ high and with a density of 33 trees ha ${ }^{-1}$ mixed with 65 year old beech trees (Fagus sylvatica), 10-20 m high and 61 trees $\mathrm{ha}^{-1}$. There is no undergrowth present. The soil consists of a $0.25 \mathrm{~m}$ acid sandy top layer, which is a weathering residue of the underlaying calcareous glacial till deposit of $2.7 \mathrm{~m}$ thick, textured sandy loam. They are covered with an organic layer. The glacial till is underlain with completely impermeable Jurassic heavy clay, which forms a tight lower boundary of the basin. The water table fluctuates from 0.15 $0.45 \mathrm{~m}$ below the soil surface between January and May, to 

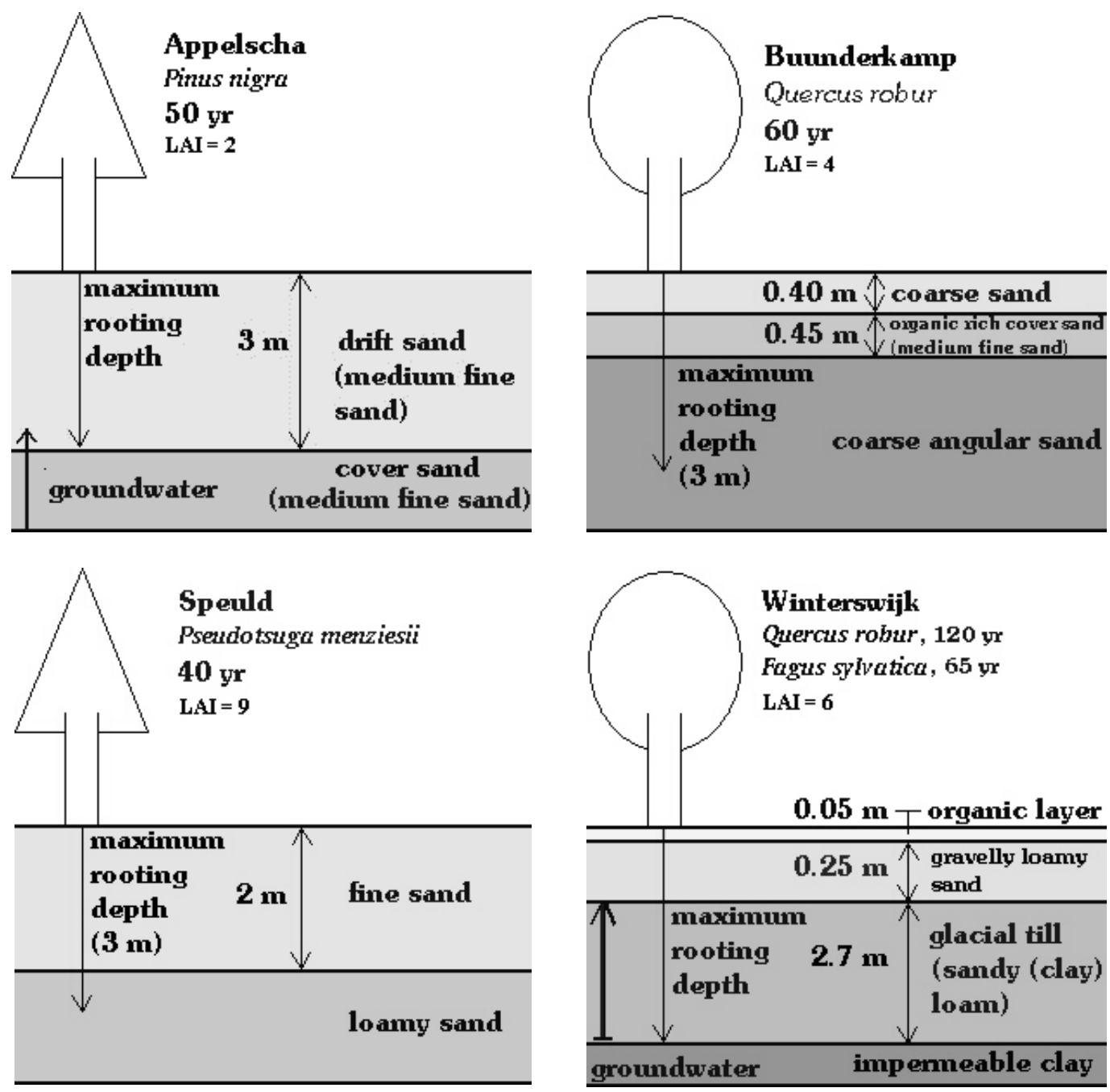

Fig. 1. Schematic overview of the four different sites

1.50-3.00 $\mathrm{m}$ in November. More detailed information on the research site is given by Bouten et al. (1992a) and Tietema (1992).

\section{MODEL DESCRIPTION}

The SWIF (Soil Water in Forested Ecosystems) model is used to describe vertical water flow and root water uptake in the unsaturated soil zone. The model also includes soil evaporation and lateral drainage in the saturated zone.

The SWIF model uses finite differences to solve the Richards equation:

$$
C(h) \frac{\partial h}{\partial t}=\frac{\partial}{\partial z}[K(h)(\partial h / \partial z+1)]-S(h, z)
$$

where $C$ is the differential water capacity $\left(\mathrm{m}^{-1}\right), t$ is time (d), $z$ is height $(\mathrm{m}), \mathrm{h}$ is soil water pressure head $(\mathrm{m}), K(h)$ is the unsaturated hydraulic conductivity characteristic $\left(\mathrm{m} \mathrm{d}^{-1}\right)$, and $S$ is a sink term accounting for root water uptake $\left(\mathrm{d}^{-1}\right)$. A full description is given by Tiktak and Bouten (1992). In the present paper, the water uptake module only is described.

The root water uptake $\left(S_{i}\right)$ from a layer $i$ is calculated from the potential uptake $\left(S_{i}^{*}\right)$ and a reduction function $f\left(\mathrm{~h}_{\mathrm{i}}\right)$ for that layer (Belmans et al., 1983):

$$
S_{i}=f\left(h_{i}\right) S_{i}^{*}
$$

with

$$
\begin{array}{ll}
f(h)=0 & h \leq h_{1} \\
f(h)=1-\left[\frac{h-h_{2}}{h_{1}-h_{2}}\right]^{a} & h_{1}<h<h_{2} \\
f(h)=1 & h_{2} \leq h \leq h_{3}
\end{array}
$$




$$
\begin{array}{ll}
f(h)=1-\left[\frac{h_{3}-h}{h_{3}-h_{4}}\right] & h_{3}<h<h_{4} \\
f(h)=0 & h>h_{4}
\end{array}
$$

where the empirical parameter $a$, wilting point $h_{1}(\mathrm{~m})$, water stress reduction point $h_{2}(\mathrm{~m})$, beginning of optimal transpiration in the wet trajectory $h_{3}(\mathrm{~m})$ and anaerobosis point $h_{4}(\mathrm{~m})$ are calibration parameters. A graphical representation of Eqns. (3)-(7) is given in Fig. 2.

The potential uptake from a layer is calculated by distributing the total potential transpiration $T^{*}\left(\mathrm{~m} \mathrm{day}^{-1}\right)$ over all soil layers according to the effective root length of a layer $\left(\Theta_{i} R_{i}\right)$ expressed as a fraction of the total effective root length of the soil profile, $\Sigma\left(\Theta_{i} R_{i}\right)$ :

$$
S_{i}^{*}=T^{*} \frac{\Theta_{i} R_{i}}{\sum\left(\Theta_{i} R_{i}\right)}
$$

where the saturation fraction $\Theta_{i}=\theta_{i} / \theta_{s, i}$ and $q_{i}$ and $q_{s, i}$ denote actual and saturated water contents of layer $i$ respectively; $R_{i}$ is the root density of layer $i$. The potential transpiration $T^{*}$ is calculated with:

$T^{*}=f_{c}(1-G) E T^{*}-\left(1-f_{t h r f}\right) / f_{i}$

where $f_{c}$ is an empirical crop factor which accounts for stand characteristics; $G$ is the canopy gap fraction; $f_{i}$ is the interception efficiency; $E T^{*}\left(\mathrm{~m} \mathrm{day}{ }^{-1}\right)$ is potential evapotranspiration calculated from daily global radiation and temperature according to Makkink (1957) and $f_{\text {thrf }}$ is the throughfall fraction. Daily rainfall is input for the model.

Using Eqn. (8), preferential uptake from layers with a high saturation fraction is simulated. This mathematical formulation of preferential uptake from relatively wet layers is a representation of a biological strategy to exploit the most effectively located roots, i.e. the short-term dynamics of the root system. Roots can exhibit highly dynamic behaviour with the growth (or death) of fine roots. In this concept, the root density used in SWIF is a quantification of the coarse, and measurable, root fraction whereas the preferential uptake-submodel represents the dynamics of the fine roots of which measurement is extremely difficult.

With an adjusted version of the model, the competition between different root systems for the available soil water is simulated. In SWIF-C (the competition version of the SWIF model) two different root systems were introduced, competing for the same water. For each root system, potential and actual water uptake were calculated for each soil layer. The model value of soil water uptake with which the new state of soil water content is calculated, is the mean value of uptake of the two separate root systems. In this way the

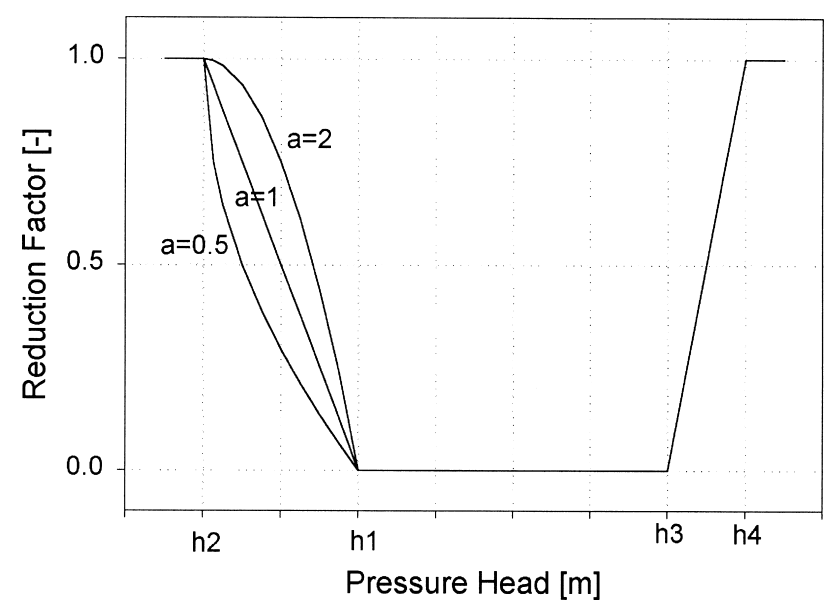

Fig. 2. A graphical representation of the reduction function used in SWIF: see Eqns. (3)-(7), a is the empirical factor of Eqn. (4)

uptake of one root system influences the availability of soil water for the other root system. The soil water uptake activity of both systems in thereby interrelated, which is important to be able to quantify the effects of competition. As the total water uptake of the individual root systems is also calculated, one can compare the integrated soil water uptake of the two different root systems and can thereby determine which one of the two root systems had the higher soil water uptake.

\section{THE ANALYSIS}

The goal of the study was to determine the optimal values for the root densities $R_{i}$ for each layer in the discretised SWIF-model.

The model as presented in the previous section combines both physical and biological characteristics of the system. In soil water flow there are the physical relationships between soil, water, gravity, etceteras, and there is the biological feature of root water uptake. These characteristics are combined in Eqn. (1) which has both the flow term and the uptake term. In this model therefore, the physics and the biology of the system interact to determine the outcome of the system. One cannot say that the root water uptake determines the soil water flow, or that the soil water flow determines the root water uptake. By a numerical solution the model calculates the results of the mutual interactions between the two features, as the uptake of water determines the flow of water and, visa versa, the flow of water determines the availability of water, and thereby the root water uptake - see Eqns. (2)-(7).

Due to these feedback relations the biology of the system, i.e. root water uptake in this study, through its effects on the soil water flow, affects its own possibilities for further root 
water uptake. For example, if all roots are concentrated in certain soil layers, the soil layers will be depleted of water sooner than other layers without roots. In this analysis this indirect feedback, the fact that the distribution of roots affects the possibilities for future root water uptake for those same roots, is used to determine what the optimal distribution of roots is for maximising the total uptake of soil water, or the equivalent actual transpiration, over a period of ten years. In this study it is therefore hypothesised that the distribution of roots throughout the soil column is a result of the tree's strategy to optimise the total soil water uptake during long periods of time. The optimal root distribution is determined by running the model ten years with different sets of root profiles, and then maximise the ten year value of actual transpiration. This means that in each run a selected root profile is used, which is not changed during the run. This study is not dealing with growth, or the process in which the optimal root distribution is obtained, but just with the static optimal outcome of distribution of roots over a soil column. Therefore, the physical-biological interactions are not changed during one model-run, and the Richards' equation (Eqn. (1)) continues to be a solution to the physics of soil water flow.

The 10-year period was chosen to cancel effects of one extreme year on the calculated optimal root distribution. For an easy comparison of the four sites, all model configurations had 14 soil layers, and therefore 14 root densities. The specific soil layer discretization is given in Table 1. To prevent numerical errors around interfaces of soil layers with different soil physical characteristics, sometimes a thin layer was introduced. Each root density could have a value between zero and one. As real tree root densities of one layer next to another layer do not differ too much, a coupling between the root densities of the adjacent soil layers was introduced: the difference in density between one layer and the layers adjacent to this layer could not be higher than a relative value of 0.5 .

Traditional optimisation techniques are not suited to optimise such high numbers of parameters (i.e. 14). Therefore genetic algorithms were used (Gallagher and Sambridge, 1994). Genetic algorithms are optimisation search methods inspired by the natural process of evolution. The main idea of genetic algorithms is to evolve the best possible solution from random elements using the basic components of the nature's evolutionary method: encoding of organisms as genetic (DNA) data structures, recombination, mutation and persistence of desirable characteristics. Each parameter is represented as a gene, which is encoded as a binary string. A set of genes, representing a parameter combination, forms a chromosome. In this model study, with 14 parameters, a chromosome consisted of 14 genes. The method applied here is similar to the one applied by Van Wijk and Bouten (2000). First, a random initial population of 100 chromosomes was generated. For each chromosome the performance of the SWIF-model with that parameter-combination was calculated. Depending on their performance, chromosomes were selected, and a new population was created. In this new population the chromosomes of the selected parametercombinations were present, and also new chromosomes that were created by crossover and point mutations of the selected chromosomes. In this way the parameter space was further explored in order to improve the solution. Of this new population the performance of each parameter-combination was calculated again, a selection took place, a new generation was created, etceteras. The length of optimisation

Table 1. Soil layer discretisation used for SWIF-NC (Non-Competition) and SWIF-C (Competition) for the four sites

\begin{tabular}{llllllll}
\hline Layer & $\begin{array}{l}\text { Appelscha } \\
\text { Depth } \\
(\mathrm{m})\end{array}$ & $\begin{array}{l}\text { Thickness } \\
(\mathrm{m})\end{array}$ & $\begin{array}{l}\text { Buunderkamp } \\
\text { Depth } \\
(\mathrm{m})\end{array}$ & $\begin{array}{l}\text { Thickness } \\
(\mathrm{m})\end{array}$ & $\begin{array}{l}\text { Speuld } \\
\text { Depth } \\
(\mathrm{m})\end{array}$ & $\begin{array}{l}\text { Thickness } \\
(\mathrm{m})\end{array}$ & $\begin{array}{l}\text { Winterswijk } \\
\text { Depth } \\
(\mathrm{m})\end{array}$ \\
\hline 1 & $0.00-0.05$ & 0.05 & $0.00-0.05$ & 0.05 & $0.00-0.05$ & 0.05 & $0.00-0.05$ \\
2 & $0.05-0.10$ & 0.05 & $0.05-0.10$ & 0.05 & $0.05-0.10$ & 0.05 & $0.05-0.10$ \\
$(\mathrm{~m})$
\end{tabular}


was chosen 200 generations, because after this optimisation period no clear improvements were present anymore in the calculated water uptake.

The key point in this analysis was the definition of the performance of the SWIF-model using a certain parameter combination. For each model configuration, a separate performance criterion was defined. For the SWIF-model without competition (SWIF-NC) the performance criterion is defined as the amount of water extracted from the soil over a period of ten years. The higher this amount, the 'fitter' the parameter-combination.

For the SWIF-model with competition (SWIF-C) this total amount of water extraction could not be used as fitnesscriterion, as the amount of water extracted by a certain root profile is influenced by the root profile 'against' which it is competing. Therefore a so-called evolutionary game (Sigmund, 1993) was introduced. A population of 30 root profiles was used and each root profile played ten times against another root profile. For each root profile a score is calculated of the number of matches won and the number of matches lost. A match is won by the root profile with the highest 10-year water uptake. The number of matches won is used as the fitness criteria. The more matches a root profile wins, the more likely it will be that it is present in the next generation. Also here 200 generations were used.

In this analysis several assumptions are made about the functioning of the system. Here the most important ones are listed. First, it is assumed that the distribution of roots does not affect the physical properties of the system. All the soil physical characteristics are kept the same for each layer during the testing of several root distributions. Another assumption is the logical result of using a non-spatial distributed point model: spatial homogeneity of the physical and biological characteristics of the system. In the comparison of SWIF-C and SWIF-NC, the implicit assumption is that the model is both valid at stand scale (SWIF-NC) and on the individual tree scale, the only scale at which strategic competition for water can be imagined (SWIF-C). Furthermore, in the analysis of SWIF-C the trees compete for all water available: the assumption here is that the roots are totally mixed in the soil layers for which he model is applicable: this can be seen in a spatial context as a location in between the two trees.

\section{SPECIFIC MODEL INFORMATION FOR THE}

\section{DIFFERENT SITES}

Model parameterisations are based on extensive monitoring programmes and model calibrations (Bouten et al., 1992a,b; Musters et al., 2000). An overview of the specific model parameterisation for the locations is given in Table 2 and
Figs. 1 and 3. For Appelscha, SWIF was adapted to include the evapotranspiration of the undergrowth, parameterised according to Vrugt et al. (2001); this amounts to about 30\% of the total forest ecosystem evapotranspiration in that site. One-third of the total calculated Makkink evapotranspiration was assigned to the undergrowth with a rooting depth of $0.25 \mathrm{~m}$ and the remainder was assigned to the trees of which the root distribution was optimised. The coefficient ' $a$ ' of Eqn. (4) had a value of 0.43 for the tree-roots and a value of 0.67 for the undergrowth roots (Vrugt et al., 2001), thereby representing a smaller sensitivity to soil water stress of the undergrowth than that of the trees.

All meteorological input variables were measured at permanent measurement locations of the Royal Netherlands Meteorological Society close to the different forest sites, although there were only minor differences in the meteorological inputs for the four sites.

\section{SENSITIVITY ANALYSIS}

Optimised values do not give insight into the sensitivity of the calculated water uptake to changes in the root densities. If this sensitivity is low the properties of the optimised root system do not give much information about the relationship between trees, roots and soil. Therefore, a sensitivity analysis was applied to quantify the sensitivity of the total soil water uptake in the ten-year period to deviations from the optimised root profile.

Each root optimisation (SWIF-NC and SWIF-C) had a slightly different sensitivity analysis. For SWIF-NC for each layer separately, the maximum and minimum values of the root density $\left(R_{i}\right)$ for which the total water uptake was within $0.25 \%$ of the total value simulated with the optimised root profile were determined. This value of $0.25 \%$ seems extremely low, but it is calculated over the total time period. In the Netherlands, there are only relatively short periods of soil water stress, which lead to a decrease of potential transpiration of some $5-20 \%$. During the test of the effects of changes in the root density of one layer, the values of the other layers were kept at their optimised value.

The sensitivity analysis of SWIF-C could not be performed in same way as for SWIF-NC, because the two root systems influence the water uptake of each other. Therefore, one root system was defined as the optimal root profile at the end of the evolutionary game (after 200 generations), and the sensitivity analysis was applied to the competing root profile. At each analysis the total uptake value of the optimised root system was calculated and compared to that of the competing root system. Of the competing root system, similar to the SWIF-NC analysis, the root density of one layer is varied, and the other values 
Appelscha

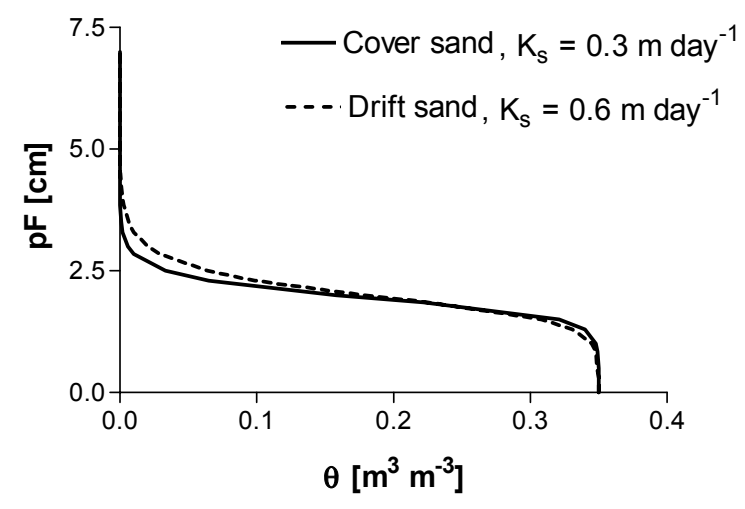

Speuld

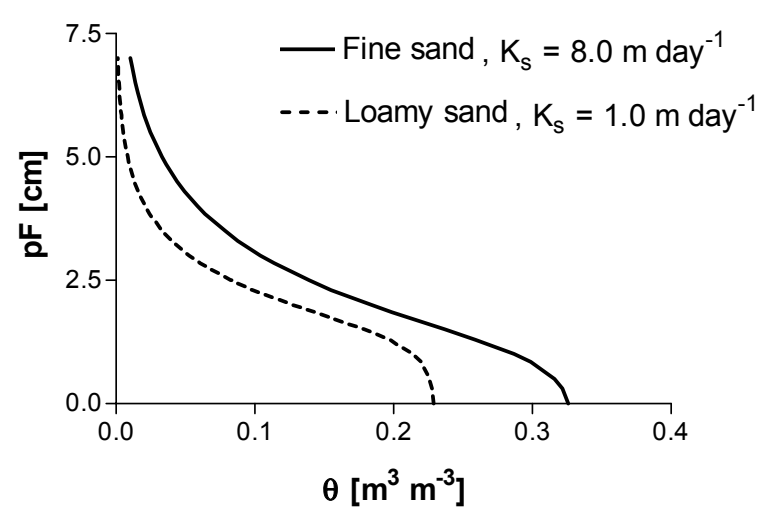

\section{Buunderkamp}

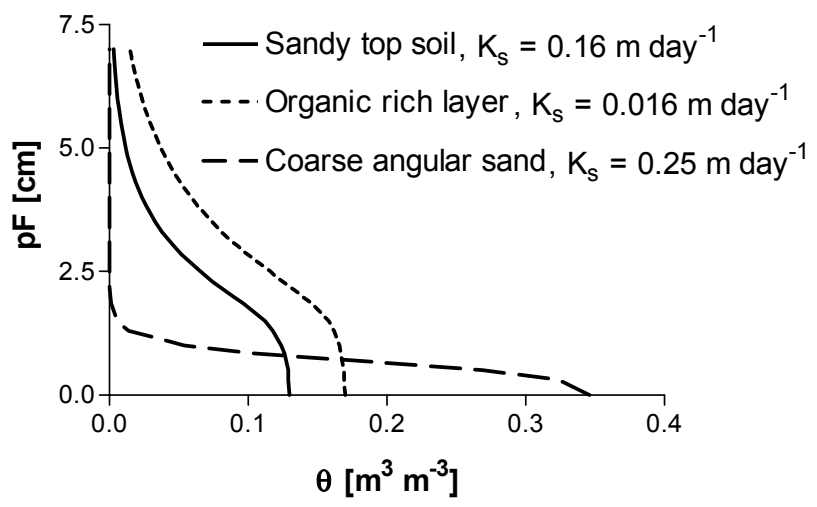

Winterswijk

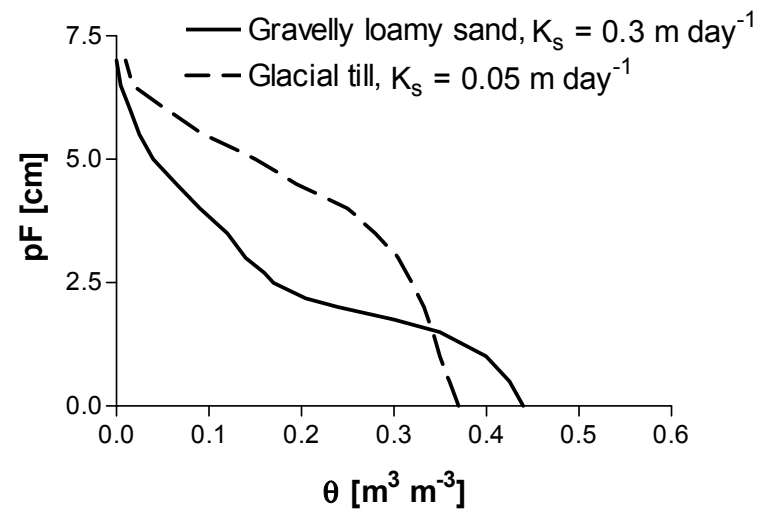

Fig. 3. Soil physical characteristics of the four different sites ( $p F$ is $\log (-h)$ in which $h$ is soil water pressure head (cm), $K_{s}$ is the saturated hydraulic conductivity characteristic $\left(\mathrm{m} \mathrm{d}^{-1}\right)$ and $q$ is soil water content $\left.\left(\mathrm{m} \mathrm{m}^{-3}\right)\right)$

Table 2. Overview of transpiration coefficients for the sites Appelscha, Buunderkamp Speuld and Winterswijk (for explanation of the symbols see text)

\begin{tabular}{lllll}
\hline Coefficients & Appelscha & Buunderkamp & Speuld & Winterswijk \\
\hline Crop factor $f_{\mathrm{c}}$ & 1.0 & Winter: 0.0 & 1.0 & Winter: 0.0 \\
& & $\begin{array}{l}\text { Summer: } 1.15 \\
\text { Winter: } 0.8\end{array}$ & 0.1 & Wummer: 1.3 \\
Canopy gap & 0.4 & Summer: 0.3 & & Summer: 0.1 \\
fraction G & & -4.0 & -6.0 & Dependent on \\
$h_{1}[\mathrm{~m}]$ & -1.0 & & & potential evaporation: \\
& & & & $0.0001 \mathrm{~m} \mathrm{~d}^{-1}-1.0 \mathrm{~m}$ \\
& & & & $0.001 \mathrm{~m} \mathrm{~d}^{-1}-0.75 \mathrm{~m}$ \\
& -25 & -30 & -60 & -25 \\
$h_{2}[\mathrm{~m}]$ & -0.30 & -0.02 & -0.02 & -0.02 \\
$h_{3}[\mathrm{~m}]$ & -0.20 & -0.01 & -0.01 & -0.01 \\
$h_{4}[\mathrm{~m}]$ & 0.43 (trees) & 0.35 & 1 & 0.25 \\
$a$ & 0.67 (undergrowth) & & & \\
& & & & \\
\hline
\end{tabular}


are kept at the optimised root density value. Also here for each layer a maximum and minimum value of the root density $\left(\mathrm{R}_{\mathrm{i}}\right)$ were determined for which the total amount of water extracted from the soil was within a certain percentage of the total value simulated with the optimised root profile. Again a percentage $0.25 \%$ gave results with which differences between different soil depths and different sites could be shown most clearly.

\section{Results and discussion}

Firstly, the results of the optimisation runs are discussed: can the results of the different sites be understood in relation to the site characteristics? Then the differences between the two model configurations are discussed: what is the effect of introducing competition into the SWIF-model? After this, the uptake patterns of the optimised root profiles are presented, followed by a comparison of the results of the optimisation with measured root profiles. Finally, the analysis is evaluated.
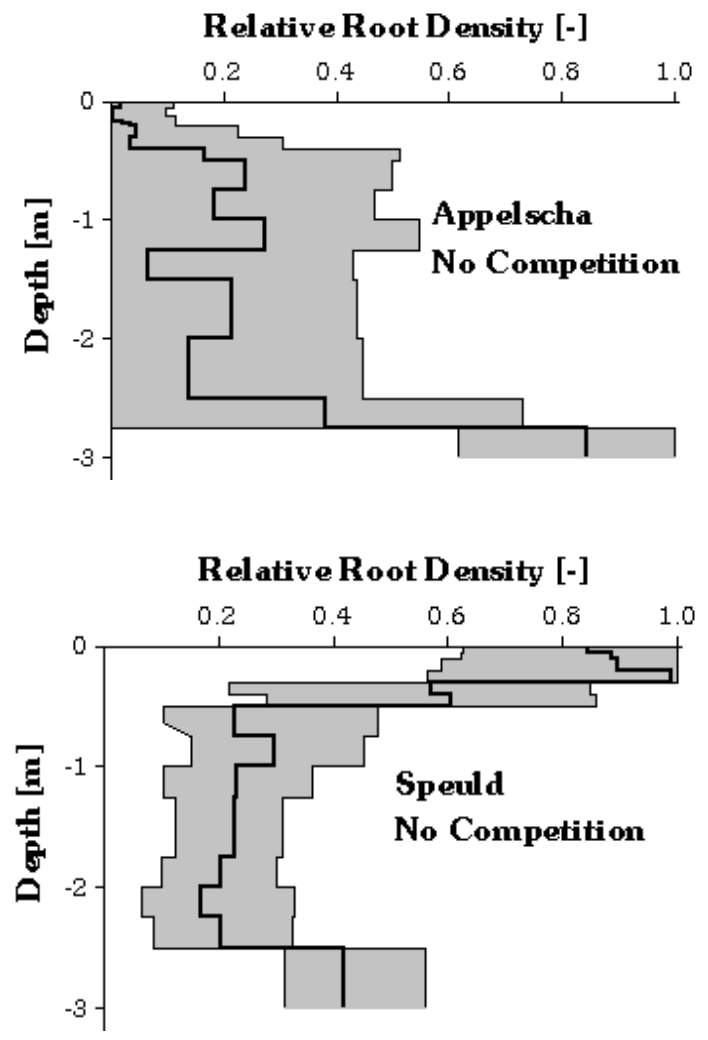

\section{NON-COMPETITION}

Figure 4 shows the results of different root optimisations and the sensitivity analysis for SWIF-NC. The thick lines represent the optimised root profiles of the four locations, and the grey areas represent the results of the sensitivity analysis in which the sensitivity of the total amount of transpiration to changes in the relative root distribution over ten years was calculated. The results of the optimised root profiles will be discussed and then placed in perspective with the results of the sensitivity analysis.

The differences in simulated root distributions between the locations were clear. In SWIF-NC the roots of Appelscha were preferentially located in the lower soil layers (close to the groundwater) whereas the Speuld, and especially the Winterswijk roots were located in the upper soil layers. While in Appelscha the roots try to profit from the water available from the groundwater, in Winterswijk the roots seem to avoid the water table that builds up above the tight lower boundary of heavy clay and fluctuates from $0.15-$ $0.45 \mathrm{~m}$ below the soil surface between January and May. This can be explained by several differences in the model formulation and the model parameterisation between
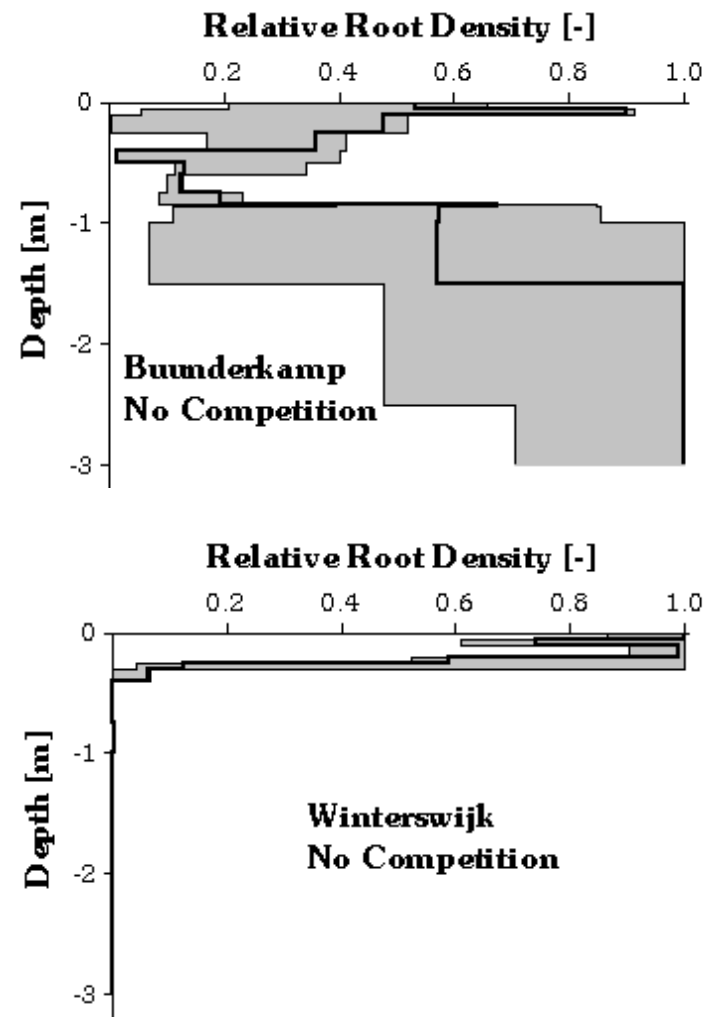

Fig. 4. Results of root profile optimisation of SWIF-NC together with sensitivity analysis (the thick lines represent the optimised root profiles of the four locations, and the grey areas represent the results of the sensitivity analysis) 
Winterswijk and Appelscha. First, in Appelscha there is a strong competition between the undergrowth and the trees for the available surface water entering the system via rain. As the roots of the undergrowth are less sensitive to water stress, the undergrowth dries out the top soil in summer, and the trees are forced to situate their roots in the deeper soil layers. A second aspect is the difference in soil characteristics: Winterswijk soil characteristics show a higher buffer capacity for water, while most of the water is drained to the groundwater level in Appelscha. Soil water is stored in the top sand layer and hardly drained beyond the rooting depth. A third aspect is the dynamics of the groundwater level: in Appelscha the groundwater level is relatively stable and not influenced much by the roots. In Winterswijk, because of the almost impermeable heavy clay layer, water builds up in the winter, and the only way to decrease the ground water level is by root water uptake as no lateral flow takes place in the model parameterisation obtained for this site (Bouten et al., 1992a). However, in the model formulation there is a strong reduction of soil water uptake in the wet trajectory $(\mathrm{h}>-0.02 \mathrm{~m}$; see equations 6 and 7), and therefore a strong selection against root profiles that locate roots in that part of the soil profile. It is much more preferable to locate the roots just above the groundwater level and use this water indirectly via capillary rise. A fourth aspect in Winterswijk working against locating roots in the glacial till layer is its water retention characteristic. Figure 3 shows that its differential capacity for water $(\mathrm{dq} / \mathrm{dh})$ is low in the range of $0>\mathrm{h}>-30 \mathrm{~m}$, compared to the sandy layer characteristic. This means that when the soil dries, a limited uptake of water can decrease the soil pressure into the dry soil water stress trajectory. The combination of point 3 and 4 shows that during almost the whole year the glacial till layer is not attractive to locate roots in: in winter and beginning of the spring there is uptake reduction because of the wetness of the soil, whereas later in the summer there is reduction because of the low pressure heads.

Both Speuld and Buunderkamp showed a small decrease in the optimised root distribution in the uppermost soil layer as compared to the layer just beneath, although this is not indicated in the minimum and maximum values (represented by the grey area in Fig. 4) in the sensitivity analysis. This effect is probably caused by competition for soil water in the uppermost soil layer between roots and soil evaporation. As a relation between soil water content and soil evaporation is not included, soil evaporation can continue in dry situations in which the roots are already experiencing soil water stress. It will therefore not be optimal to locate too many roots in the uppermost layers, because they will be in competition with soil evaporation when the soil dries out.
The Speuld root distribution also showed a small increase in the density of roots located in the lowest soil layer. This is an effect of the soil layer discretisation: in the summer in a soil water stress period, the roots will extract all available water from the soil layers where they are present. The soil water content of the soil layers just beneath the rooted zone will therefore be higher than that of the rooted soil layers, and some upward water flux will occur. It will therefore be a good strategy to locate a significant number of roots at the point of that small upward water flux, for use in extreme soil water stress periods. The Buunderkamp site showed a complex root distribution: many roots were in the upper and lower soil layers, while there were relatively few roots in the intermediate soil layers.

The grey ranges in Fig. 4 show the sensitivity over a tenyear period to changes in the relative root distribution of the total amount of transpiration. The relatively low sensitivity was caused by the short periods of water stress in the simulated period of ten years. Winterswijk showed the highest sensitivity to changes in the root densities, whereas Appelscha and Buunderkamp had larger grey ranges.

The sensitivity analysis also showed differences in sensitivity for the different soil layers of one plot. Appelscha had higher values (small grey surface) in the upper layers and lower values in soil layers beneath a depth of $30 \mathrm{~cm}$, the rooting depth of the undergrowth. As the under-storey was less sensitive to water stress than the trees (Vrugt et al., 2001), it is optimal to locate only a few roots in the upper soil layers, and any increase in the number of roots located there results in a relatively strong decrease in total water uptake. The Speuld root distribution showed a uniform sensitivity, whereas the Winterswijk configuration showed a high sensitivity in the lowest soil layers: a small deviation from the optimised amount of $0 \mathrm{~m}^{3} \mathrm{~m}^{-3}$ roots resulted in a clear decrease in total transpiration. The Buunderkamp root distribution showed complex behaviour in the sensitivity analysis: low sensitivity in the upper soil layers, high sensitivity in the middle soil layers and low sensitivity in the lowest soil layers.

\section{COMPETITION (SWIF-C) VERSUS NON- \\ COMPETITION (SWIF-NC)}

The results of SWIF-C (Fig. 5) showed an upward drive in the root distributions if compared to SWIF-NC (Fig. 4), except for Winterswijk. When there is no competition between root systems, water introduced into the system by rain will drain to lower soil layers if no roots are present. If the distribution of a single root system is optimised, it is not important whether the root system captures the water at the 

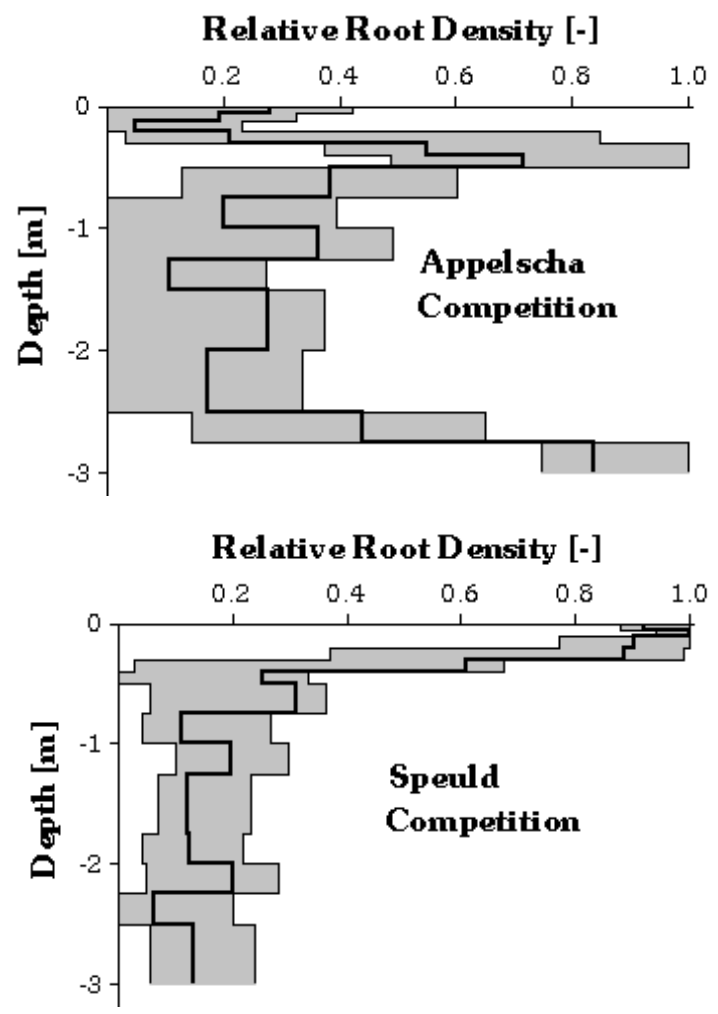

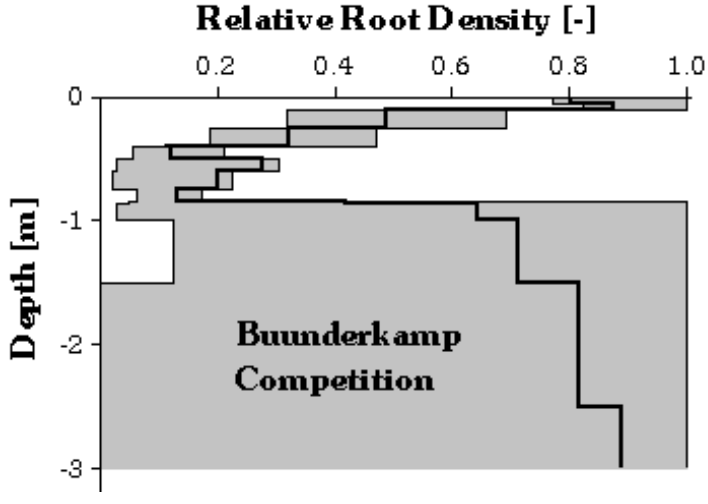

Relative Root Density [-]

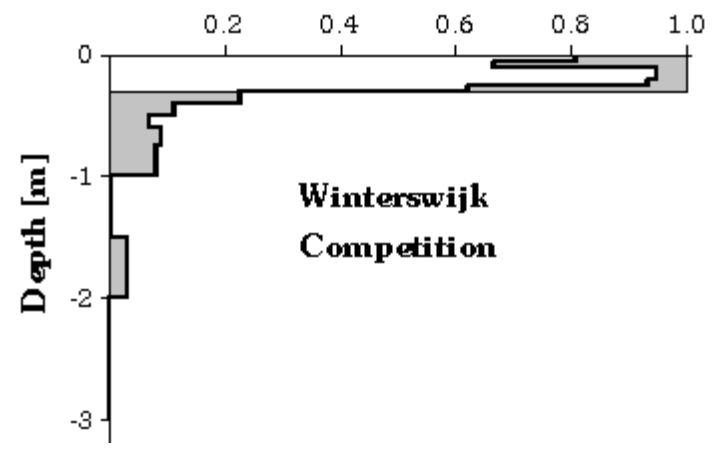

Fig 5. Results of root profile optimisation of SWIF-C together with sensitivity analysis (the thick lines represent the optimised root profiles of the four locations, and the grey areas represent the results of the sensitivity analysis)

uppermost soil layers or at lower soil layers. This changes when competition is included in the model: if a root system is not present in the top layers the competing root system will capture the water before it reaches the lower soil layers.

This effect is most clearly visible in the results of Appelscha. The optimal strategy for root distribution for Appelscha in SWIF-NC was to locate most of the roots in the lowest soil layers, just above the groundwater table. In water stress situations this root distribution could profit from capillary rise from the groundwater, whereas infiltrating rainfall water would reach the roots eventually. In SWIF-C this strategy was no longer optimal, because the struggle for infiltrating water would be lost to a root distribution strategy that also locates roots in the layers just beneath the roots of the under-storey, in the upper $25 \mathrm{~cm}$.

Winterswijk was the only site in which the optimised root profile of SWIF-C tended to locate more roots in the deeper soil layers than SWIF-NC. Although the sensitivity analysis indicates that the glacial till layer was not important (the grey surfaces extended only to the side with less roots), this trend was robust and did not disappear when the genetic algorithm optimisation was continued for another 200 generations. Probably this effect is caused by the fact that, in the competition optimisation, a root profile with all the roots located in the uppermost soil layers is not optimal when competing with a root profile that also has many roots in the deeper soil layers. With roots in the deeper soil layers the ground water level will be lower in early summer, and the root profile with all roots in the uppermost layers cannot access the water becoming available through capillary rise.

For Speuld and Buunderkamp, the differences between the results of SWIF-C and SWIF-NC were more subtle. For Speuld the increase in roots in the lowest soil layer disappeared due to the upward drive of the roots in the competition. Buunderkamp showed no large differences in the optimised root distributions, but the results of the sensitivity analysis showed a clear effect of competition. In SWIF-C, soil water uptake showed an increased sensitivity to changes in the rooting density of the upper soil layers, while the sensitivity to changes in root densities of the lower soil layers was extremely low.

The high allocation of roots, both for SWIF-NC as for SWIF-C, in the coarse angular sand layers of the Buunderkamp is probably caused by the formulation of water stress and preferential water uptake in SWIF. In spring, all soil layers have about the same high soil water content and all roots can take up the water required for transpiration. This results in drying of the soil, especially in the lower soil layers where rainfall does not infiltrate because it is stored in the upper soil layers or taken by roots. For the coarse 
angular sand layers this means that very low soil water contents are reached, in the order of $0.005 \mathrm{~m}^{3} \mathrm{~m}^{-3}$ in summer. The model describes a potential preferential water uptake using the saturation fraction which is defined as $\Theta_{i}=\theta_{i} / \theta_{s, i}$, and the root fraction according to Eqn. (8). With very low soil water content values in the coarse angular sand layers in summer, this leads to a negligible potential uptake from the coarse angular sand and thus to a low sensitivity to the number of roots located in these layers (see Fig. 4). It is, therefore, an optimal strategy to locate a high number of roots in the coarse angular sand layers to extract as much water as possible in spring, while in summer these roots are no longer important for water extraction. This effect is illustrated in Fig. 6. The relative amount of water uptake (i.e. below $0.85 \mathrm{~m}$ in depth) was higher in winter and spring than in summer and autumn. In summer and autumn almost all water uptake took place in the upper soil layers. In absolute terms the soil water uptake in summer and autumn from the lowest soil layers was even slightly lower than that in winter \& spring, although the water demand was much higher. This low uptake from the lower soil layers led also to a low sensitivity of the total amount of water transpired in the period of ten years to changes in the number of roots located in these layers, because the roots in these soil layers are effective only in spring.

In this rooting strategy optimisation there was no 'cost' differentiation related to a certain allocation of roots. A logical assumption could be that roots located in lower soil layers are more costly than roots located in upper soil layers: water extracted from deeper soil layers must by transported within the roots to the upper soil layers. If such a cost function were included, this would lead to a decrease in the density of roots in the lower soil layers, especially in the coarse sand layers of the Buunderkamp as the sensitivity to

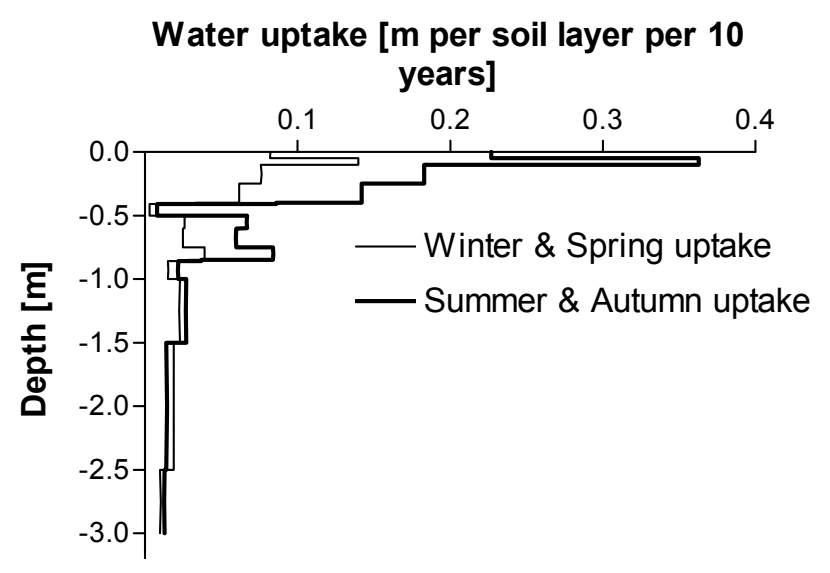

Fig. 6. Ten year total soil water uptake per season at the Buunderkamp site changes in the root densities in these layers is extremely small.

\section{UPTAKE PATTERNS}

In Figure 7 the total 10-year uptake values in the SWIF-NC configuration are given as a total and for each soil layer separately, both for SWIF-NC and SWIF-C optimised root profiles. In Table 3 the total 10-year uptake values of the four sites and the two models are given together with the values for the potential transpiration. For all sites, the total uptake for SWIF-NC was higher than that for SWIF-C: this was not surprising because the root profiles of SWIF-NC were derived by maximizing this value, whereas in SWIF$\mathrm{C}$ the roots also had to deal with a competing root system. The higher sensitivity of water uptake to changes in the root distribution in Winterswijk shown in Figure 4 and 5 is also reflected in the large difference between the ten-year uptake of the optimised SWIF-NC and that of the SWIF-C profile. The results of Table 3 show that the simulated total reduction of the potential transpiration is about 10 to $20 \%$, except for the extreme case of Winterswijk.

A comparison of the uptake values over the different soil layers and the optimised root profiles shows that the relation between those two is relatively strong for Appelscha and Speuld. These sites have rather homogeneous soils with high hydraulic conductivity. Therefore, steep gradients in water content seldom occur and the preferential uptake does not have much influence. The preferential uptake clearly influences the results of the root profile optimisation in the Buunderkamp: while the root density in the coarse angular sand layers is high, the uptake is relatively low. The results from Winterswijk show that the uptake from the glacial till is negligible although SWIF-C also locates roots in this layer. This apparent discrepancy can be explained by the low differential capacity for water $(d \theta / d h)$ of the glacial till.

For the Appelscha location, the differences in the uptake patterns between SWIF-C and SWIF-NC reflect the differences in the optimised root profiles: the SWIF-NC profile had the highest water uptake in the lowest soil layers, whereas SWIF-C had large uptake in the soil layers just beneath the rooting depth of the undergrowth. The differences between the uptake patterns for the other sites between SWIF-NC and SWIF-C were only small. For all sites, most uptake takes place in the upper soil layers. The peak in the root profiles of both SWIF-NC and SWIF-C in Winterswijk at depth $0.3 \mathrm{~m}$ is reflected in a peak in uptake at that depth. The increase in root density for the SWIF-C in Buunderkamp at $0.6 \mathrm{~m}$ depth is also reflected in an increased uptake at the same value. 


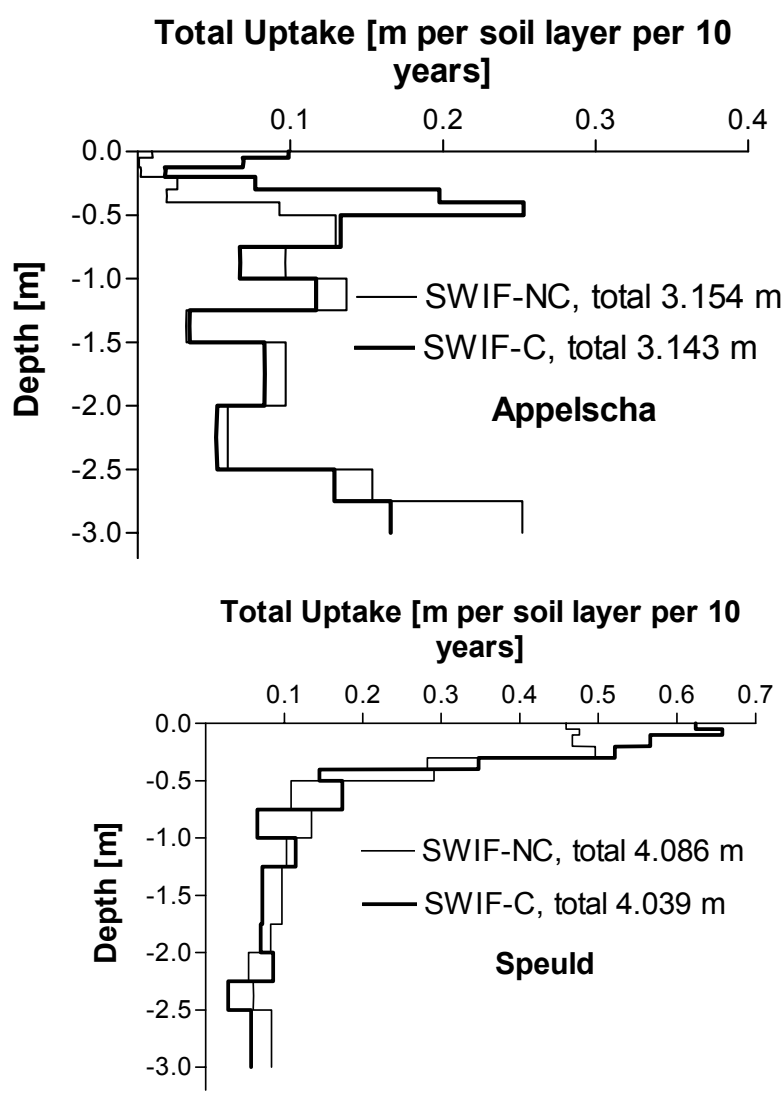

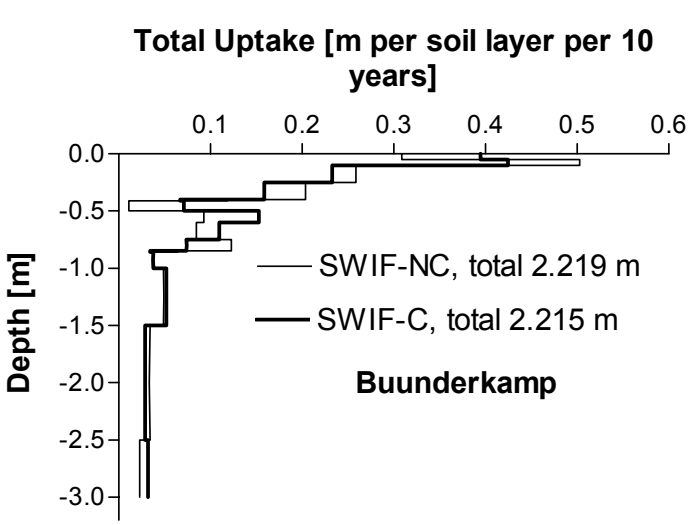

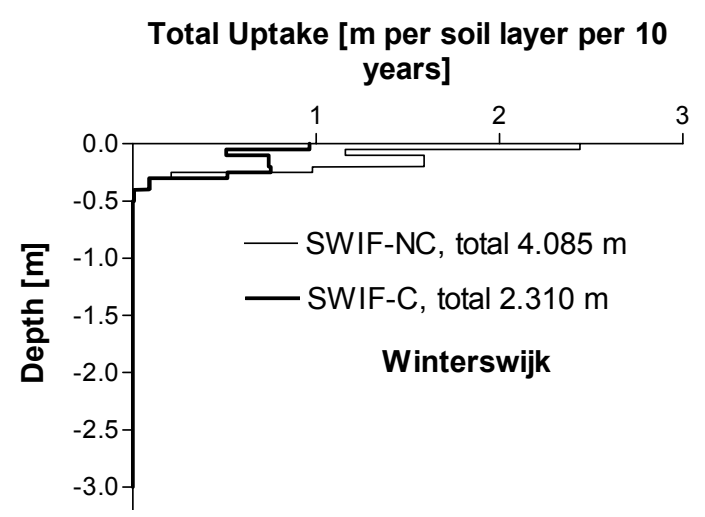

Fig. 7. Total soil water uptake in ten years for the four different sites using the optimised root profiles of SWIF-NC (no competition) and SWIF-C (competition)

Table 3. Potential and actual simulated transpiration amounts (absolute, and relative to the potential amount) over the 10-year periods for the four sites for SWIF-NC (Non-Competition) and SWIF-C (Competition).

\begin{tabular}{llll}
\hline Site & $\begin{array}{l}\text { Sim. Pot. } \\
\text { Transpiration } \\
\text { [m per 10 years] } \\
\text { (see equation 9) }\end{array}$ & $\begin{array}{l}\text { Sim. Act. } \\
\text { Transpiration with } \\
\text { SWIF-NC } \\
{[\text { per 10 years]; }} \\
\text { between brackets } \\
\text { \% of potential }\end{array}$ & $\begin{array}{l}\text { Sim. Act. Transpiration } \\
\text { with SWIF-C } \\
\text { [m per 10 years]; } \\
\text { between brackets } \\
\% \text { of potential }\end{array}$ \\
\hline Appelscha & 4.017 & $3.154(78.5 \%)$ & $3.143(78.2 \%)$ \\
Buunderkamp & 2.509 & $2.219(88.4 \%)$ & $2.215(88.3 \%)$ \\
Speuld & 4.463 & $4.086(91.6 \%)$ & $4.039(90.5 \%)$ \\
Winterswijk & 4.155 & $4.085(98.3 \%)$ & $2.310(55.6 \%)$ \\
\hline
\end{tabular}

\section{COMPARISON WITH MEASURED ROOT PROFILES}

Comparison of the simulation results with measured profiles is hampered by the fact that the root profile was optimised over a period of ten years. Short-term changes in root allocation are therefore not reflected in the results, but can be present in the measured root profiles. Another problem is the spatial variability in profiles: a point model was used, which assumes homogeneous soil, biological and hydrological features. Another problem with comparison with measurements is that unambiguous measurements are 
not available for all four sites. Available data are presented in Fig. 8. The only site for which a direct comparison is possible is Winterswijk, for which coarse root densities are measured for the whole profile. For Appelscha only quantitative root data are available for locations at which the cover sand layer, which is not accessible for roots, was $70 \mathrm{~cm}$ deep. This parameterisation was not used in this study, because it would hamper the inter-site comparison. For Buunderkamp, only qualitative measurements are available, presented in the profile description in Fig. 8 for that site. For Speuld, a detailed fine root study is available (Olsthoorn, 1998) as well as qualitative data about coarse roots.

Because of these problems and the lack of quantitative data, the discussion is concentrated on the major effects predicted by the root optimisation results. In Appelscha the most important features of the optimised root distributions were first, a limited amount of roots present in the upper soil layers, and second, a clear increase in root density just above the ground water level, which coincides with the transition between the drift and cover sand layers. The first feature, a limited density of tree roots in the upper soil layers, was not present in the measurements. At the uppermost organic layer of about $0.05 \mathrm{~m}$, grass roots only were present and no tree roots but at the other upper soil layers there was a high density of both undergrowth and tree roots. At locations where the drift sand layer was relatively thin (up to $0.5 \mathrm{~m}$ ), the amount of tree roots decreased slightly with depth, until just above the cover sand layer a clear decrease in root density was visible: a similar pattern as in the present results. In the detailed root measurements presented for a drift sand layer of $70 \mathrm{~cm}$ (Fig. 8), this increase in root density is still visible, although the increase is not very strong. However, at locations with a drift sand layer of $3 \mathrm{~m}$, as in the model parameterisation, hardly any roots were found below $2 \mathrm{~m}$ and the increase in root density just above the cover sand was not present. This difference between locations with thin and thick drift sand packages can be understood using the concept of a cost function. To allocate more roots at a depth of $1.0 \mathrm{~m}$ will cost less energy than to allocate more roots at a depth of $3 \mathrm{~m}$. The mismatch at the upper soil layers can be caused by many effects, all due to the fact that the present analysis deals only with water. For example, nutrients are also very important in determining root distributions: in the uppermost layers relatively high concentrations of nutrients can be found and, therefore, it is necessary for trees to allocate a high density of roots there.

The Speuld results agreed reasonably well with the measurements. The highest numbers of roots were found in the uppermost layers up to a depth of $0.40 \mathrm{~m}$, and lower numbers were found at the deeper soil layers, with few roots penetrating deeper into soil. The results of the detailed fine root measurements of Olsthoorn (1998) reflect this pattern. Tiktak and Bouten (1994) showed that also in the deeper soil layers, down to $2.5 \mathrm{~m}$, significant soil water uptake occurred, as predicted by the results of the present analysis.

The results of Winterswijk clearly underestimated the measured amount of roots in the glacial till, as measured in Bouten et al. (1992a). As shown in Bouten and Witter (1992), the rooting depth is the determining factor for the decrease of the groundwater table in spring; it was optimal to locate the highest root densities just above the groundwater level in winter and, in stress situations, to use the water available through capillary rise. This is especially the case for SWIF-NC, whereas in SWIF-C a few roots were located in the glacial till as a kind of safety measure. The deviation between measured and optimised root profiles may be caused by the simple assumption that hydrology is the determining factor for the root distribution. By locating the roots only in the upper $0.30 \mathrm{~m}$, the trees would be very unstable. Also the uptake of sufficient essential nutrients like $\mathrm{Ca}$ would be difficult from the acidified cover sand layer only (Bouten et al., 1992a).

The results of the Buunderkamp site clearly deviate from the measured values. The qualitative measurements of Fig. 8 showed an increase in root density in the organic rich cover sand at a depth of about $0.5 \mathrm{~m}$ compared to the soil layers just above, and almost no roots present in the coarse sand layer (Tietema, 1992). Simulation results showed only a small increase in roots present in the organic layer with a small peak present in the results of SWIF-C (see Fig. 5). In the sensitivity analysis this peak almost disappeared. Therefore, it seems that the abundance of roots in the organic rich cover sand cannot be explained from a hydrological point of view only, but is also an effect of the high abundance of nutrients available in that soil layer. Almost no roots were present in the coarse sand layers, a fact that can be explained with the results of SWIF-C.

\section{Concluding remarks}

The measured root profiles do not always reflect the optimised profiles: why then use this type of analysis? It can represent the knowledge and test hypotheses about the functioning and the distribution of roots. For example, from a hydrological point of view, the increase of roots in Appelscha just above the cover sand layer and just above the groundwater table can be explained easily. It can also be used as a negative explanation: the presence of roots in the glacial till layer in Winterswijk cannot be caused just from a hydrological point of view.

Elsewhere this kind of simulation can be used to test the effects of competition on root distributions at different sites. 


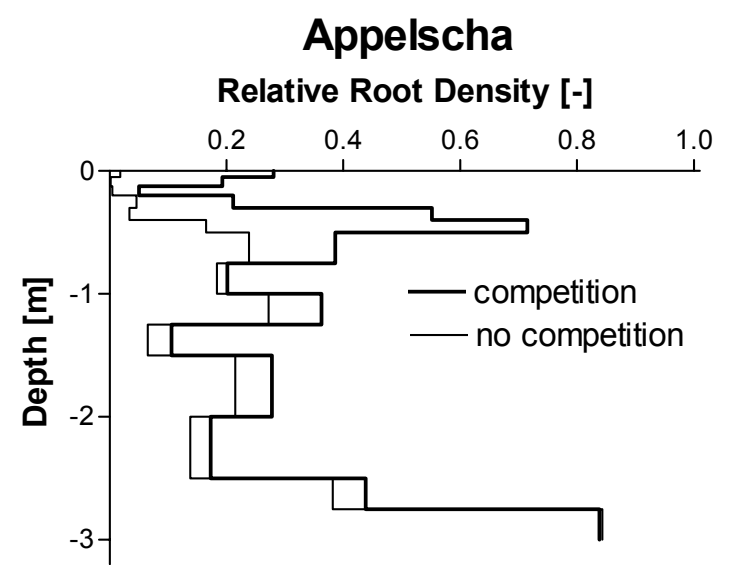

Relative Root Density [-]

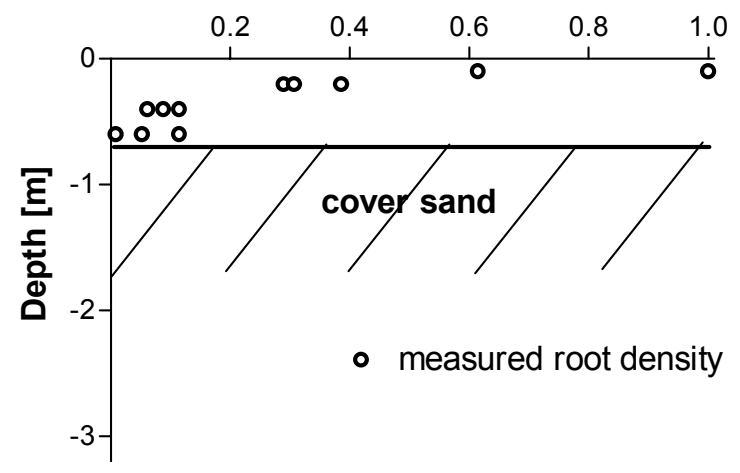

Buunderkamp

\section{Relative Root Density [-]}

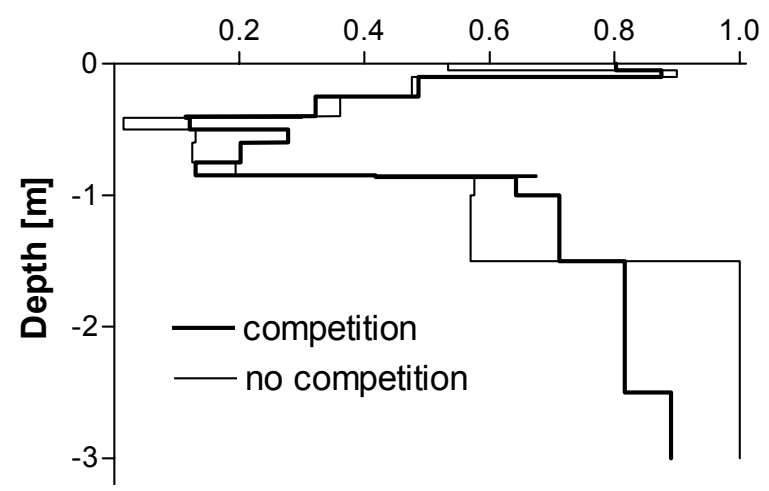

Profile description
$0-10 \mathrm{~cm} \begin{aligned} & \text { abundant very fine, fine, medium and coarse } \\ & \text { roots }\end{aligned}$ $10-20 \mathrm{~cm}$ few very fine, fine and medium roots
$20-50 \mathrm{~cm}$ abundant very fine, fine, medium and coarse $50-80 \mathrm{~cm}$ few very fine, fine, medium and coarse roots $80-100 \mathrm{~cm}$ few roots

\section{Speuld}

\section{Relative Root Density [-]}

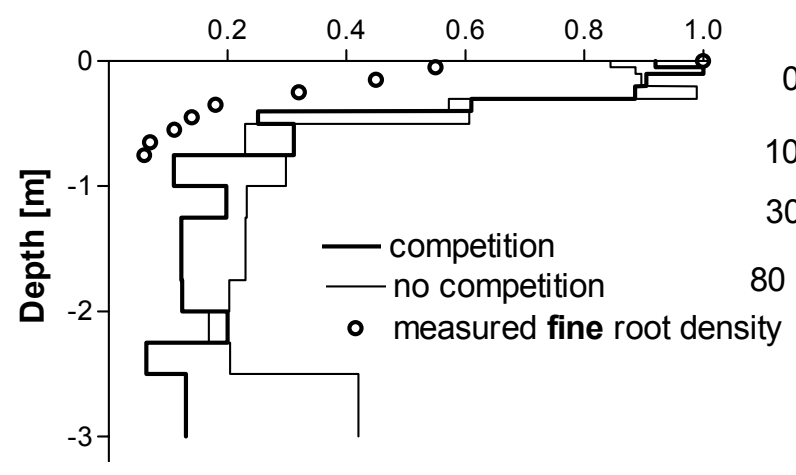

Profile description
$0-10 \mathrm{~cm}$ abundant very fine, very frequent fine, medium and coarse roots
$10-30 \mathrm{~cm}$ frequent fine, medium and coarse roots
$30-80 \mathrm{~cm}$ frequent fine, common medium and few coarse $80-110 \mathrm{~cm}$ few fine and medium roots

Winterswijk Relative Root Density [-]

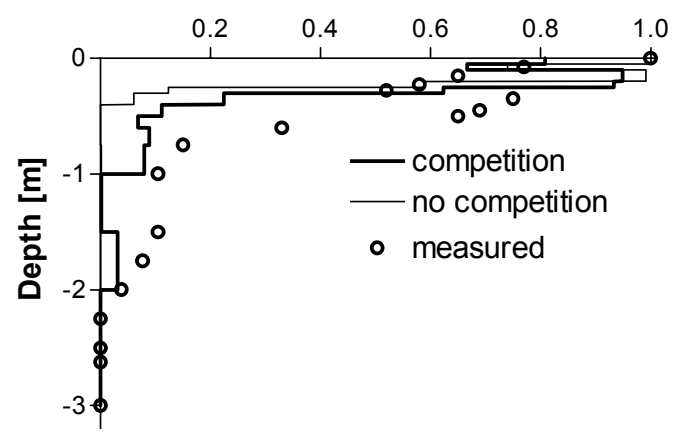

Fig. 8. Optimised root profiles of SWIF-NC (no competition) and SWIF-C (competition) together with the available measured root data for the four sites (for explanation see text) 
The results of SWIF-C showed a greater similarity to the measured root profiles than SWIF-NC, and the results were more easily interpreted in terms of root functioning, especially for the Buunderkamp site. The results, therefore, show that competition for water must be incorporated into models for this type of analysis.

The total soil water uptake over the ten-year period showed a low sensitivity to changes in the optimised root distribution. One cause is the preferential uptake as used in SWIF. If few roots are located in a certain layer, the soil water content will stay relatively high in that layer. This will lead to a positive feedback in uptake from that layer, because the saturation fraction will be relatively high. The main cause, however, is the short periods of water stress in these locations and the relative low amounts of total reduction of the potential transpiration (see Table 3). Differences in root distributions affect transpiration only in these periods and, therefore, result in minor changes in the amount of total transpiration over a period of ten years. Why then not optimise over shorter time periods, for example only the water stress periods? For the decision to optimise transpiration for a period of ten years several reasons are important. First, water uptake distributions over the different soil layers in non-water stress periods influence the soil water content distributions in water stress periods. Therefore, one cannot analyse the periods of water stress decoupled from wet periods. Another problem is that, if root distributions are optimised over shorter time periods, the boundary conditions in those periods determine the outcome of the optimisation. The period of ten years is chosen to achieve some insight into optimal strategies for root distribution over longer time scales, which can be related to distributions of the larger roots. Short-term changes in root distributions, linked to changes in the fine root distributions that can develope within weeks, were not the main issue in the research.

It is obvious that this analysis of optimal rooting strategies is only a first step towards understanding root distributions. An extensive list can be made of elements that are important for determining the actual distribution of tree roots, and that are missing in this study: nutrients, cost of water distribution within the plant, cost of rooting at a certain depth: what is difference in 'cost' between shallow and deep roots, the function of roots for increasing tree stability, etceteras. Another important simplification in this analysis is the absence of a spatial context in the model. Obviously, the spatial distribution of roots of individual trees affects the importance of competition for water between these roots. In this analysis a total mixture of roots is assumed to see what effects the including of competition into the modelanalysis has on the optimised root distributions. As in reality total mixture will not occur, the effects of competition will be over-estimated in this study. All these simplifications show that this analysis is only a first step towards understanding tree root profiles. It can, in addition to experimental work, help clarify whether hydrological processes are determining the root distributions of trees, or whether the actual measured tree root distributions are determined by other factors.

\section{Acknowledgements}

The funding by the National Research Program (NOP) 952232: "Climate change and Forest Ecosystem Dynamics in Europe" and the Universiteit van Amsterdam is gratefully acknowledged. J.M Verstraten is thanked for critical reading of an earlier draft of this paper.

\section{References}

Asseng, S., Richter, C. and Wessolek, G., 1997. Modelling root growth of wheat as the linkage between crop and soil. Plant Soil, 190, 267-277.

Belmans, C., Wesseling, J.G. and Feddes, R.A., 1983. Simulation model of the water balance of a cropped soil: SWATRE. $J$. Hydrol., 63, 271-286.

Bouten, W., 1992. Monitoring and modelling forest hydrological processes in support of acidification research. $\mathrm{PhD}$ Thesis, Universiteit van Amsterdam, Amsterdam, The Netherlands. 218 pp.

Bouten, W. and Witter, J.V., 1992. Modelling soil water dynamics in a forest ecosystem II: evaluation of spatial variation of soil profiles. Hydrol. Process., 6, 445-454.

Bouten, W., Schaap, M.G., Bakker, D.J. and Verstraten, J.M., 1992a. Modelling Soil Water Dynamics in a Forested Ecosystem I: A Site Specific Evaluation. Hydrol. Process., 6, 435-444.

Bouten, W., Heimovaara, T.J. and Tiktak, A., 1992b. Spatial patterns of throughfall and soil water dynamics in a Douglasfir stand. Water Resour. Res., 28, 3227-3233.

Canadell, J., Jackson, R.B., Ehleringerf, J.R., Mooney, H.A., Sala, O.E. and Schulze, E.D., 1996. Maximum rooting depth of vegetation types at the global scale. Oecologia, 108, 583-595.

Cowan, I.R., 1977. Stomatal behaviour and environment. Adv. Bot. Res., 4, 117: 221.

Gallagher, K. and Sambridge, M., 1994. Genetic algorithms: a powerful tool for large-scale nonlinear optimization problems. Comput. Geosci.-UK, 20, 1229-1236.

Harper, J.L., Jones, M. and Sackville-Hamilton, N.R., 1991. The evolution of roots and the problems of analysing their behaviour. In: Plant root growth, an ecological perspective, D. Atkinson (Ed.), Blackwell Scientific Publications, Oxford, 478 pp.

Jackson, R.B., Canadell, J., Ehleringer, J.R., Mooney, H.A., Sala, E.O. and Schulze, E.D., 1996. A global analysis of root distributions for terrestrial biomes. Oecologia , 108, 389-411.

Kleidon, A. and Heimann, M., 2000. Assessing the role of rooted vegetation in the climate system with model simulations: mechanism, comparison to observations and implications for Amazonian deforestation. Clim. Dynam., 16, 183-199.

Mäkelä, A., Berninger, F. and Hari, P., 1996. Optimal control of gas exchange during drought: theoretical analysis. Ann. Bot. 77, 461-467. 
Makkink, G.F., 1957. Testing the Penman formula by means of lysimeters. J. Int. Water Eng., 11, 277-288.

Musters, P.A.D., 1998. Temporal and Spatial Patterns of Root Water Uptake in an Austrian Pine Stand on Sandy Soil. PhD Thesis, Universiteit van Amsterdam, Amsterdam, The Netherlands, 143 pp.

Musters, P.A.D. and Bouten, W., 1999. Assessing rooting depths of an Austrian pine stand by inverse modelling variability in maps of soil water contents. Water Resour. Res, 35, 3041-3048.

Musters, P.A.D., Bouten, W. and Verstraten, J.M., 2000. Potentials and limitations of modelling vertical distributions of root water uptake of an Austrian pine forest on a sandy soil. Hydrol. Process., 14, 103-115

Olsthoorn, A.F.M., 1998. Soil acidification effects on fine root growth of Douglas-fir on sandy soils. $\mathrm{PhD}$ Thesis, Wageningen University, Wageningen, The Netherlands, $153 \mathrm{pp}$.

Sigmund, K., 1993. Games of Life. Penguin Books Ltd., London, $244 \mathrm{pp}$.
Tietema, A., 1992. Nitrogen cycling and soil acidification in forest ecosystems in the Netherlands. PhD Thesis, Universiteit van Amsterdam, Amsterdam, The Netherlands, 140 pp.

Tiktak, A. and Bouten, W., 1992. Modelling soil water dynamics in a forested ecosystem, III. Model description and evaluation of discretization. Hydrol. Process., 6, 445-454.

Tiktak, A. and Bouten, W., 1994. Soil water dynamics and longterm water balances of a Douglas fir stand in the Netherlands. J. Hydrol., 156, 265-283.

Van Wijk, M.T. and Bouten W., 2000. Analyzing latent heat fluxes of coniferous forests with fuzzy logic. Water Resour. Res., 36,1865-1872.

Vrugt, J.A., Bouten, W., Dekker, S.C. and Musters, P.A.D., 2001. Transpiration dynamics of an Austrian pine stand and its forest floor: identifying controlling conditions with artificial neural networks. Adv. Water Resour. (in press). 